\title{
ON THE STUNTED MOCAMBIQUE TILAPIA Oreochromis mossambicus (PETERS, 1852) (PISCES: CICHLIDAE) OF THE MATIOVILA HOT SPRING, KRUGER NATIONAL PARK
}

\section{T. HECHT}

Department of Ichthyology and Fisheries Science

Rhodes University

Grahamstown

6140

P. ZWAY

Department of Nature Conservation

National Parks Board of Trustees

Private Bag X402

Skukuza

1350

\begin{abstract}
A stunted population of Oreochromis mossambicus occurs in the Matiovila Hot Sulphur Spring in the Kruger National Park. The growth of the fishes can best be described by the Von Bertalanffy equation $\mathrm{L}_{\mathrm{t}}=184,6\left(1-\mathrm{e}^{-0.154(1+0.286)}\right) \mathrm{mm}$ SL. Breeding occurs throughout the year and the smallest sexually mature female was $35 \mathrm{~mm} \mathrm{SL}$. The fish from this locality were morphometrically compared to another stunted population and to a population of 0 . mossambicus from a large impoundment. Speculative reasons for and advantages of stunting are presented.
\end{abstract}

\section{Introduction}

The phenomena of stunting or dwarfing in tilapiine fishes has been the subject of interesting research (Worthington 1929; Ricardo 1939; Du Plessis 1951; Garrod \& Elder 1960; Soulsby 1960; Hickling 1961; Whitehead 1962; Coe 1965, 1966; Welcomme 1965; Iles \& Holden 1969; Iles 1973; Bowen 1979; Hecht \& Jackson in prep.). However, as tilapiine fishes are used for culture purposes in most warm water regions of the world, attention has been focused on how to overcome stunting rather than on the phenomenon itself.

The most comprehensive study on stunting, dwarfing or runting in fish is probably that of Iles (1973), in which he analyses the various possible causative factors, the significance of stunting and characteristics of stunted populations. Considering the review of Iles (1973) and the study of Bowen (1979) on Oreochromis mossambicus in Lake Sibaya we distinguish between two 
types of stunting. Firstly, it being a reversable phenotypic response to an environmental constraint such as food availability and quality (i.e. inhibited somatic growth) and secondly as a phenotypic adaptation, also reversable, to take advantage of a particular set of environmental conditions (e.g. accelerated earlier sexual maturation).

The Matiovila population of Mocambique tilapia, Oreochromis mossambicus was first discovered by the Warden of the Kruger National Park during a distributional survey of the fishes of the park (Pienaar 1978).

Figure 1 shows the location $\left(31^{\circ} 14^{\prime} \mathrm{E} / 23^{\circ} 01^{\prime} \mathrm{S}\right)$ of the Matiovila Hot Spring, in which this isolated population occurs. Figure 2 is a diagrammatic sketch of the spring showing the various water, fish and benthic sampling stations. Except for the open sandy area the perimeter of the entire locality is fringed with tambotie trees (Spirostachys africana) and shrub vegetation succeeded by some of the tallest mopani trees (Colophospermum mopane) in the Kruger National Park. Palgrave (1977) with reference to tambotie trees mentions that they often occur along rivers and streams and in areas with brackish soils (U. de V. Pienaar pers. comm.). Numerous tracks in the open sandy area show that large numbers of different types of game frequent the spring. Among these the following were seen and identified; elephant, lion, impala, warthog, zebra, wildebeest, giraffe, hyaena, kudu, waterbuck, buffalo and sable antelope.

The deepest part of the system is the blind gulley, with a maximum depth of one meter. The remainder of the system is shallow, ranging in depth from $10-15 \mathrm{~cm}$ in the eye, to approximately $45 \mathrm{~cm}$ at Station 5, whereafter the water flows into a reed and bullrush swamp (Phragmites australis and Typha

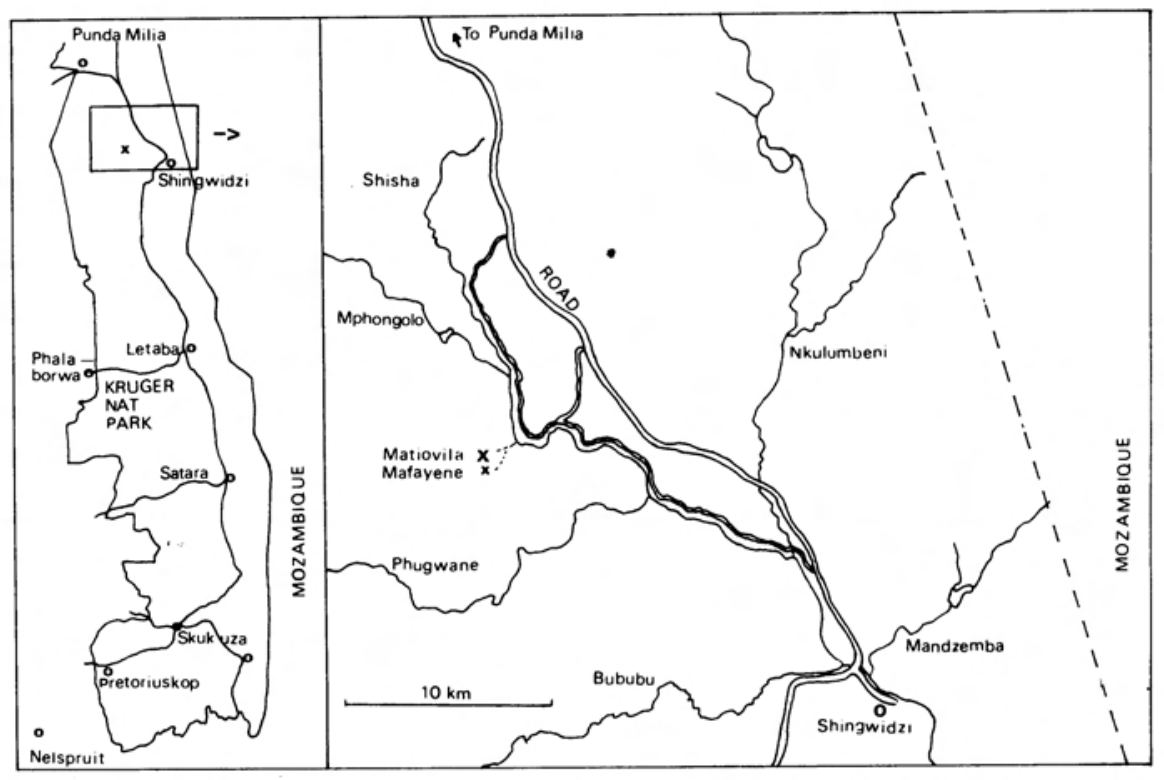

Fig. 1. The location of the Matiovila Hot Spring in the Kruger National Park. 


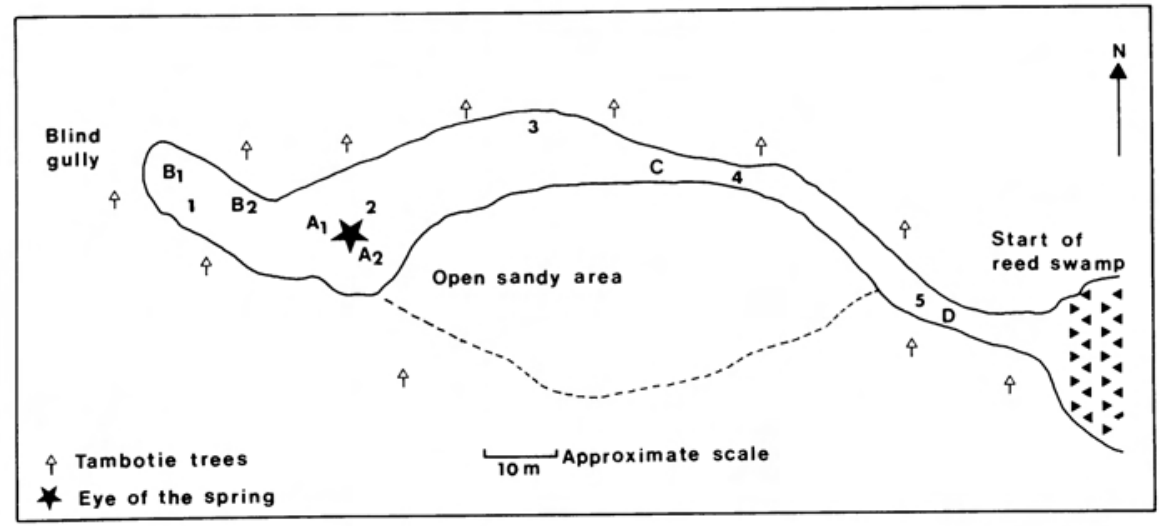

Fig. 2. A diagrammatic sketch of the Matiovila Hot Spring, showing the fish collecting sites (1-5) and the water and benthos sampling sites (A, B, C and D).

latifolia capensis). The reed swamp occasionally extends down to the Mphongolo River during years of high rainfall (J. Kloppers pers. comm.).

Two theories may be offered as to how the fishes got into the spring. Either they migrated upstream from the Mphongolo River during a season of heavy rainfall or possibly the eggs and fry were transported there by other animals, such as birds, and then escaped to survive, as postulated by Jubb (1967). The former theory is probably more likely than the latter. This uncertainty is unfortunate as it would have been interesting to know how long it took for the fish to become stunted or "adapted" to this habitat. In a study by Hecht \& Jackson (in prep.) on a population of stunted tilapia at Klein Tshipise in Venda $\left(22^{\circ} 31^{\prime} \mathrm{S} / 30^{\circ} 43^{\prime} \mathrm{E}\right)$ it was found that stunting occurred within five years.

The aim of the present study was to establish whether the fish are in fact stunted and if so, to account for the phenomenon.

\section{- Material and Methods}

To investigate the phenomenon the fish were morphometrically compared to another stunted population and also to a "normal" population of this species. All morphometric data are expressed as a percentage of standard length. Moreover, the growth rate as well as some aspects of their reproductive and feeding biology were investigated. The sagittal otoliths were also examined to possibly distinguish population differences.

From the distribution of the fish in the system and the specimens captured at the various fishing stations it was estimated that the total population probably does not exceed 400 individuals. A total of 64 specimens were captured at Stations 1-5, of which a size'range of 50 fish were fixed and preserved. These ranged from 29 to $105 \mathrm{~mm}$ standard length. Four females were returned to the water as they carried larvae in their buccal cavities. The remaining 10 fish were transported back to the laboratory alive for 
comparative physiological/haematological work (Van Vuuren \& Hecht in prep.). Table 1 shows some of the physico-chemical properties of the water measured during June 1981. U. de V. Pienaar (pers. comm.) and one of us (P.Z.) have on several occasions observed the fish in the eye of the spring where the maximum temperature of $35,6^{\circ} \mathrm{C}$ was recorded.

Table 1

Some physico-chemical properties of the waters of the Matiovila (Hot) and the Mafayene (Cold) sulphur springs in the Kruger National Park

\begin{tabular}{|c|c|c|c|c|c|c|}
\hline \multirow[b]{2}{*}{ Stations } & \multicolumn{4}{|c|}{ MATIOVILA } & \multicolumn{2}{|c|}{ MAFAYENE } \\
\hline & A & B & $\mathrm{C}$ & $\mathrm{D}$ & A & B \\
\hline Oxygen $(\mathrm{ml} / \mathrm{l})$ & 1,9 & 8,7 & 6,6 & 8,75 & & \\
\hline Oxygen (\% sat.) & 28,4 & 93,6 & 89 & 94 & & \\
\hline $\mathrm{pH}$ & 7,65 & 7,8 & 7,8 & 7,8 & & \\
\hline Conductivity (mS/m) & 585 & 380 & 542 & 418 & & \\
\hline Turbidity (\%) & 50 & 18 & 48 & 32 & & \\
\hline $\mathrm{NH}_{4}{ }^{+}-\mathrm{N}(\mathrm{ppm})$ & 1,3 & 0,07 & 1,3 & & & \\
\hline Phosphate (ppm) & 0,06 & 0,05 & 0,06 & & 0,1 & 0,08 \\
\hline $\mathrm{SO}_{4^{2-}}(\mathrm{ppm})$ & 340 & 440 & 390 & 385 & 500 & 600 \\
\hline $\begin{array}{l}\text { Total Hardness } \\
\quad\left(\mathrm{mg} / 1 \mathrm{CaCO}_{3}\right)\end{array}$ & 990 & 1155 & 1085 & 1087 & 1485 & 2420 \\
\hline Temperature $\left({ }^{\circ} \mathrm{C}\right)$ & 35,6 & 17,5 & 29,2 & 18,0 & 18,0 & 17,9 \\
\hline
\end{tabular}

In another nearby sulphur spring, the Mafayene spring, which is approximately $0,75 \mathrm{~km}$ to the south east of the Matiovila spring (Fig. 1), no fish were observed after a thorough search. The Mafayene spring is a cold spring (eye temperature $18{ }^{\circ} \mathrm{C}$ during June 1981). Table 1 also shows some of the physico-chemical properties of the Mafayene waters.

An indication of the length-at-age is the most fundamental of parameters upon which to classify a population of fişh as being stunted. For this purpose the sagittal otoliths and scales of the 50 preserved specimens were removed. In order not to damage the specimens, otoliths were removed from the capsula auditiva from underneath the operculum.

The otoliths were embedded in clear epoxy resin rods and sectioned at 0,1 $\mathrm{mm}$ through the nucleus. The sections were mounted with DPX clear mountant onto glass slides and examined at $25 \times$ magnification under a stereo microscope. Of the 50 sections examined 32 showed distinct opaque and hyalin zones (i.e. 64\%). One opaque and one hyalin zone were interpreted as one years growth on the assumption that only a single opaque and hyalin zone is deposited per year. The data were fitted by the method of least squares regression analysis to the Von Bertalanffy growth equation in the form of $\mathrm{L}_{\mathrm{t}}=\mathrm{L} \infty\left(\mathrm{l}-\mathrm{e}^{-\mathrm{K}\left(\mathrm{t}^{-} \mathrm{O}\right.} \mathrm{O}^{\prime}\right)$, where $\mathrm{L}_{\mathrm{t}}=\mathrm{SL}(\mathrm{mm})$ at age in years, $\mathrm{L} \infty=$ maximum theoretical SL, $\mathrm{K}=$ rate at which $\mathrm{L} \infty$ is attained and $\mathrm{t}_{\mathrm{o}}=$ the hypothetical age at which the fish was at zero length (Ricker 1975). 
The otoliths of the fish from the three populations were examined as these structures have on numerous occasions been successfully used to distinguish not only between species but also between different populations of the same species (Hecht 1978). All the morphological terms used in the otolith descriptions are those of Hecht (1978).

Five scales were also removed from each fish from an area below the lateral line and above the pectoral fin. The scales were cleaned and mounted between glass slides. Scale projections were examined but no age marks were discernible on any of the scales.

A portion of the ovary of each female was removed and examined under a stereo microscope to evaluate the state of oozyte maturation, in order to determine the length at sexual maturity.

A Friedlander Mudgrab with a $255 \mathrm{~cm}^{2}$ effective grab surface area was used to sample the substratum at four stations to obtain an indication of food availability.

\section{Results}

A. Comparative morphometry and meristics

Table 2 gives a comparison of the Matiovila fish with fish of a similar size from the Luphephe/Nwanedi impoundment in Venda $\left(30^{\circ} 25^{\prime} \mathrm{E} / 22^{\circ} 39^{\prime} \mathrm{S}\right)$ and from another population of stunted tilapia from the Klein Tshipise hot spring in Venda. Figure 3 illustrates the fishes from the three localities. There are no significant morphometric differences among the three populations, except as illustrated in Fig. 3 which shows that the Matiovila fish do not develop a concave snout as early as the fish from Klein Tshipise. There is an overall closer relationship between the Matiovila and the Klein Tshipise fish than between the Matiovila fish and those from the Luphephe/Nwanedi dams. The concave snout is normally only attained by males of the species after sexual maturation (Jubb 1967). Hecht \& Jackson (in prep.) in their study on the stunted fish from Klein Tshipise found that males as well as females attain a concave snout. Females attained this condition after sexual maturation although the males showed this phenomenon before attaining sexual maturity. The only striking meristic difference between the fish from the three localities is that the Matiovila fish have either three or four rows of villiform teeth in both the upper and lower jaw, whereas the others have five or six such rows, the latter being the general norm for this species (Jubb 1967).

Table 2

Comparative morphometric and other data of Oreochromis mossambicus from Matiovila, Klein Tshipise and Luphephe/Nwanedi $(\bar{x} \%$ of SL and range)

\begin{tabular}{llll}
\hline & Matiovila & Klein Tshipise & Luphephe/Nwanedi \\
\hline Headlength & $36,2(34,1-39,3)$ & $36,1(32,8-40,2)$ & $33,9(32,3-35,5)$ \\
Depth & $36,4(33,4-39,0)$ & $36,6(29,5-40,9)$ & $38,9(36,9-40,7)$ \\
Interorbital & $11,1(9,4-13,0)$ & $11,7(9,5-14,9)$ & $10,1(6,3-12,4)$ \\
Horiz. $\varnothing$ eye & $9,6(7,1-12,1)$ & $8,6(7,2-9,4)$ & $10,0(7,9-12,4)$
\end{tabular}




\begin{tabular}{llll}
\hline & Matiovila & Klein Tshipise & Luphephe/Nwanedi \\
\hline Vert. $\varnothing$ eye & $9,4(6,9-12,2)$ & $8,0(7,0-8,9)$ & $9,4(7,4-11,2)$ \\
Predorsal & $40,9(37,8-46,1)$ & $37,7(34,6-41,5)$ & $39,8(36,6-42,4)$ \\
Postorbital & $15,6(14,7-19,0)$ & $15,2(9,9-18,1)$ & $13,4(12,3-14,6)$ \\
Preorbital & $7,2(5,9-8,7)$ & & \\
Snout length & $12,9(10,7-14,8)$ & $11,8(8,5-14,3)$ & $10,5(9,6-11,4)$ \\
Length caudal peduncle & $13,0(10,1-16,6)$ & $13,9(11,9-15,7)$ & $13,8(11,9-15,5)$ \\
Least depth caudal peduncle & $13,4(9,2-14,9)$ & $13,1(11,0-14,9)$ & $14,2(12,4-15,8)$ \\
Otolith length & $4,82 \pm 0,39$ & $4,48 \pm 0,6$ & $5,04 \pm 0,48$ \\
Otolith breadth & $3,16 \pm 0,25$ & $3,02 \pm 0,32$ & $3,32 \pm 0,21$ \\
Otolith thickness & $1,05 \pm 0,08$ & $0,90 \pm 0,12$ & $1,11 \pm 0,12$ \\
Gillrakers-ant.arch & $15-22$ & $18-22$ & $14-24$ \\
Total LL scales & $29-34$ & $31-36$ & $26-34$ \\
Dors./Ventr. LL scales & $17-21 / 11-15$ & $17-20 / 11-17$ & $15-20 / 9-14$ \\
Dorsal fin formula & XIV-XVI,10-11 & XIII-XVII,10-11 & XIV-XVII,10-12 \\
Anal fin formula & III,9-10 & III,9-10 & III,9-10 \\
& & & \\
\hline
\end{tabular}

The total length (TL), standard length (SL) relationship of the Matiovila fish is best expressed by the linear regression equation $\mathrm{TL}(\mathrm{mm})=1,611+1,264$ $\mathrm{SL}(\mathrm{mm})\left(\mathrm{r}^{2}=1,0\right)$.

There are no significant differences in the morphology of the otoliths of the three populations. The sagittae of $O$. mossambicus are rounded posteriorly, bluntly pointed anteriorly and the entire perimeter is lobed to denticulate. The dorsal and ventral margins are convexly curved. The sulcus acusticus is relatively shallow and distinctly divided into an ostium and a cauda and comprises approximately $95 \%$ of the total otolith length. The ostium flares anteriorly and the cauda has a short postero-ventral angle. The posteroventral angle of the Matiovila fish otoliths is not as pronounced as in the Luphephe/Nwanedi and Klein Tshipise fish otoliths ( $c f$. Figs 4a, b \& c). The colliculi are poorly defined. The crista superior is present while the crista inferior is absent. The excisura ostii is either present or absent. The rostrum is prominent, while the anti-rostrum is either minute or absent. The otoliths are medially convex and laterally concave. The differences that are evident between the sagittae of the fish from the three localities can all be ascribed to intraspecific variation and are not the fore regarded to be of any significance.

\section{B. Age and growth}

The observed length-at-age data were fitted to the Von Bertalanffy growth equation, which for this population was found to be $\mathrm{L}_{\mathrm{t}}=184,6\left(1-\mathrm{e}^{-0.145(\mathrm{t}+0.286)}\right)$ $\mathrm{mm}$, where $\mathrm{L}_{\mathrm{t}}=\mathrm{SL}$ at age $\mathrm{t}$ in years. Although male tilapiine fishes generally grow at a slightly faster rate than the females (Bruton \& Allanson 1974; Hecht 1980), the present data for males and females were lumped. This was done mainly as a result of the relatively small sample and the reluctance to take more fish from the spring due to the fact that the population is limited and isolated.

The largest fish caught was a male of $105 \mathrm{~mm} \mathrm{SL}$. In comparison to the fish from both the Luphephe/Nwanedi dams as well as from Klein Tshipise the 

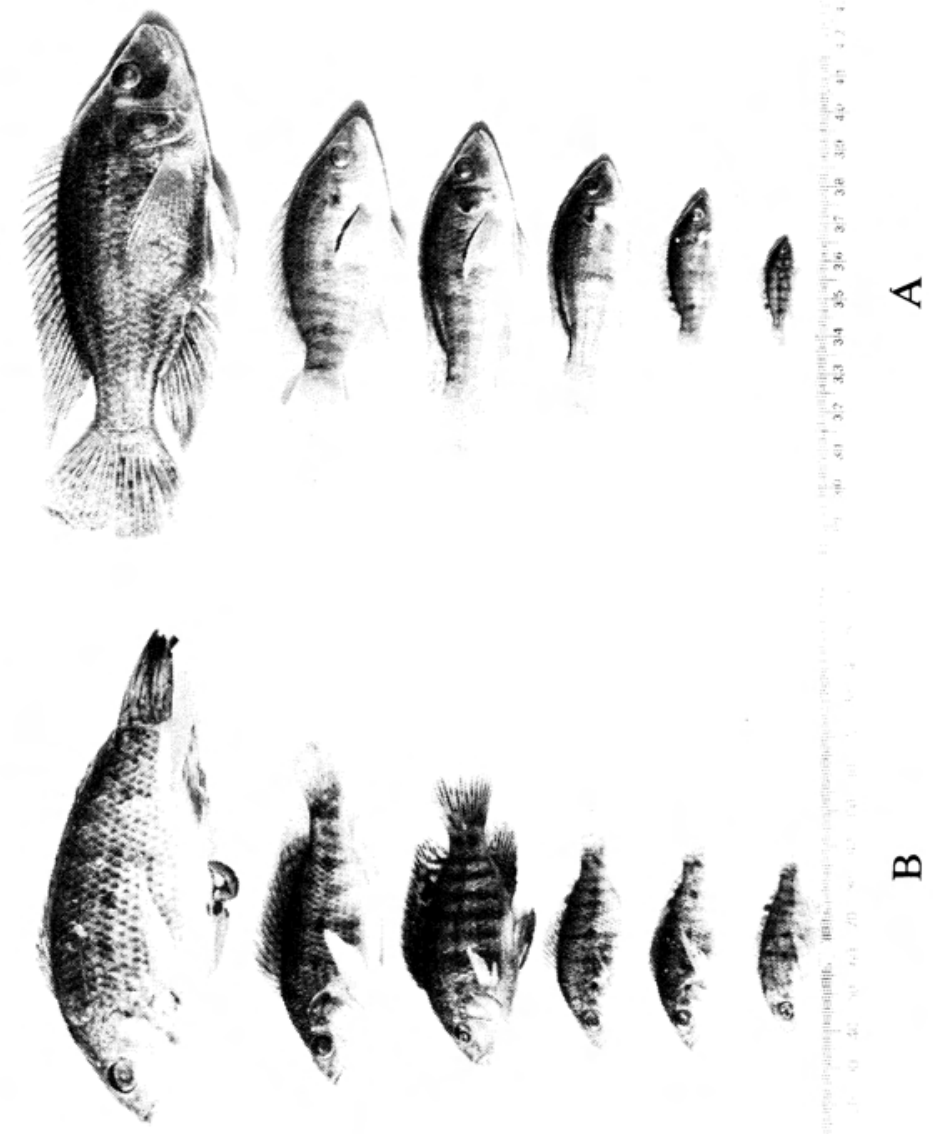

$\infty$
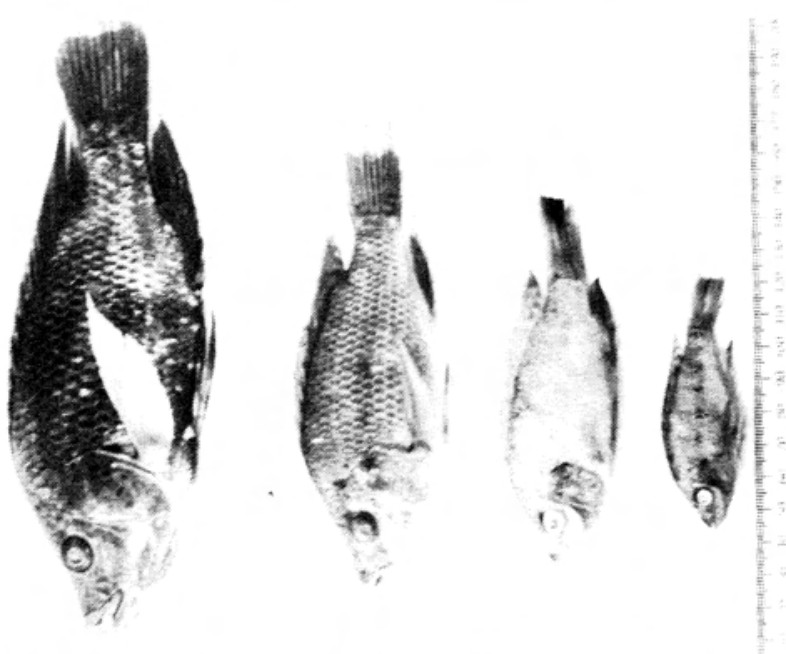

Fig. 3. Oreochromis mossambicus from (A) the Matiovila Hot Spring, (B) the Luphephe/Nwanedi dams and (C) from the Klein Tshipise Hot Spring. 


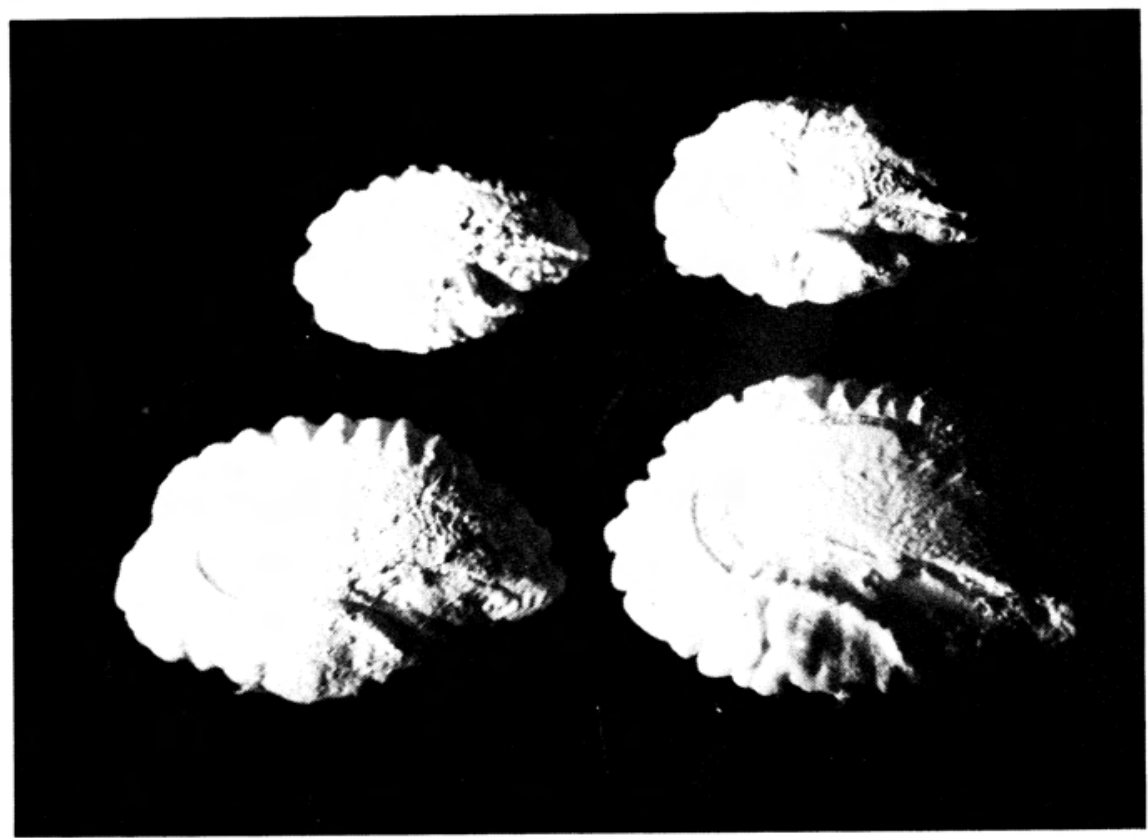

Fig. 4a. The sagittal otoliths of Oreochromis mossambicus from the Matiovila Hot Spring.

Matiovila fish have undergone dramatic stunting. Figures $3 \& 5$ illustrate the growth of the fish from the three localities.

\section{Notes on reproduction}

Due to the small sample available we could not determine the size class at which $50 \%$ of the population attain sexual maturity. Nevertheless the smallest female with ripe ovaries was $35 \mathrm{~mm}$ SL i.e. at an age of one year. In comparison, the smallest sexually mature female from Klein Tshipise was a fish of $51 \mathrm{~mm}$ SL and fish from the Luphephe/Nwanedi dam attain sexual maturity at approximately $140 \mathrm{~mm} \mathrm{SL}$ at $2+$ years of age.

As mentioned earlier four females with larvae in their mouths were also caught but these were returned to the spring. As the fish were caught in winter (June 1981) it can possibly be concluded that the Matiovila fish breed throughout the year. One of us (P.Z.) has also observed mouth brooding females in the summer, autumn and spring months.

\section{Note on food availability and feeding}

No organisms were found in the substratum samples taken in close proximity of the eye of the spring (Table 3 ). This may be due to the high temperatures and the chemical composition of the water. The general pattern that emerged is that the further away from the eye the higher the occurrence of benthic organisms. Chironomids are the dominant organisms, of which remains were also found in the gut of all the fish. 


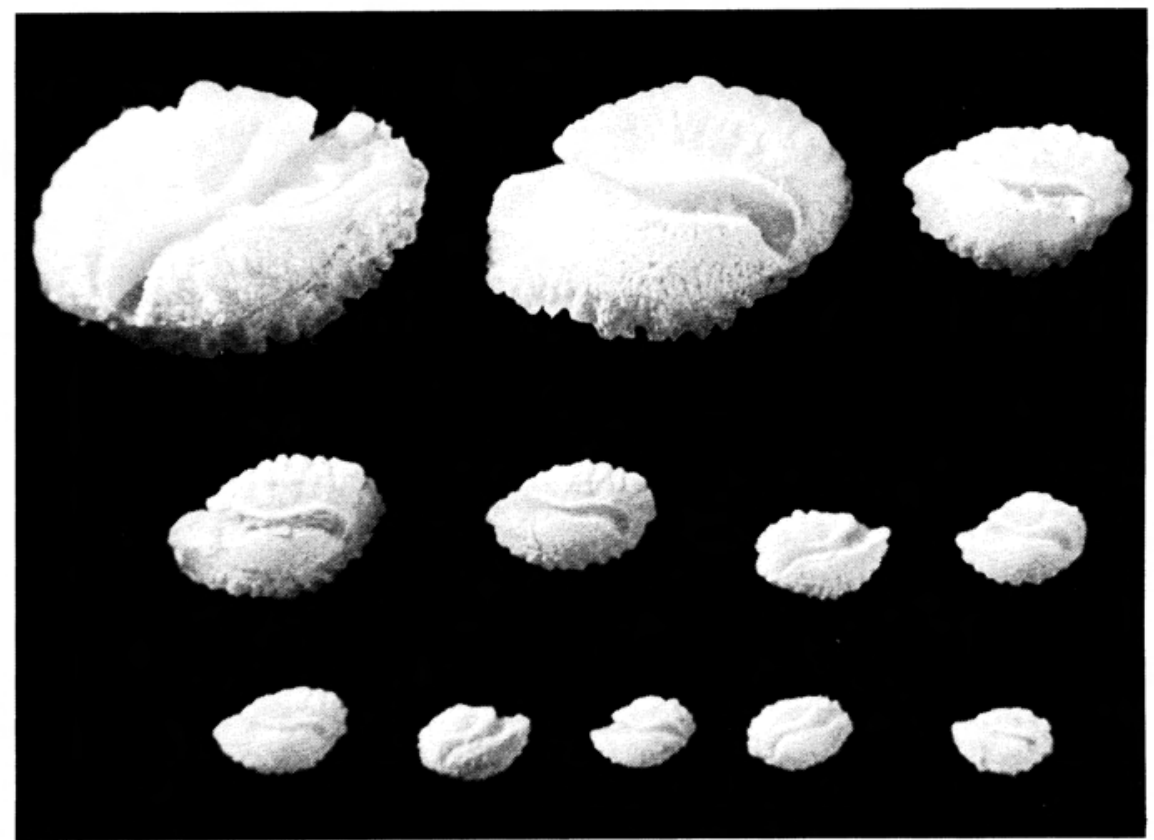

Fig. 4b. The sagittal otoliths of Oreochromis mossambicus from the LuphepheNNwanedi dams.

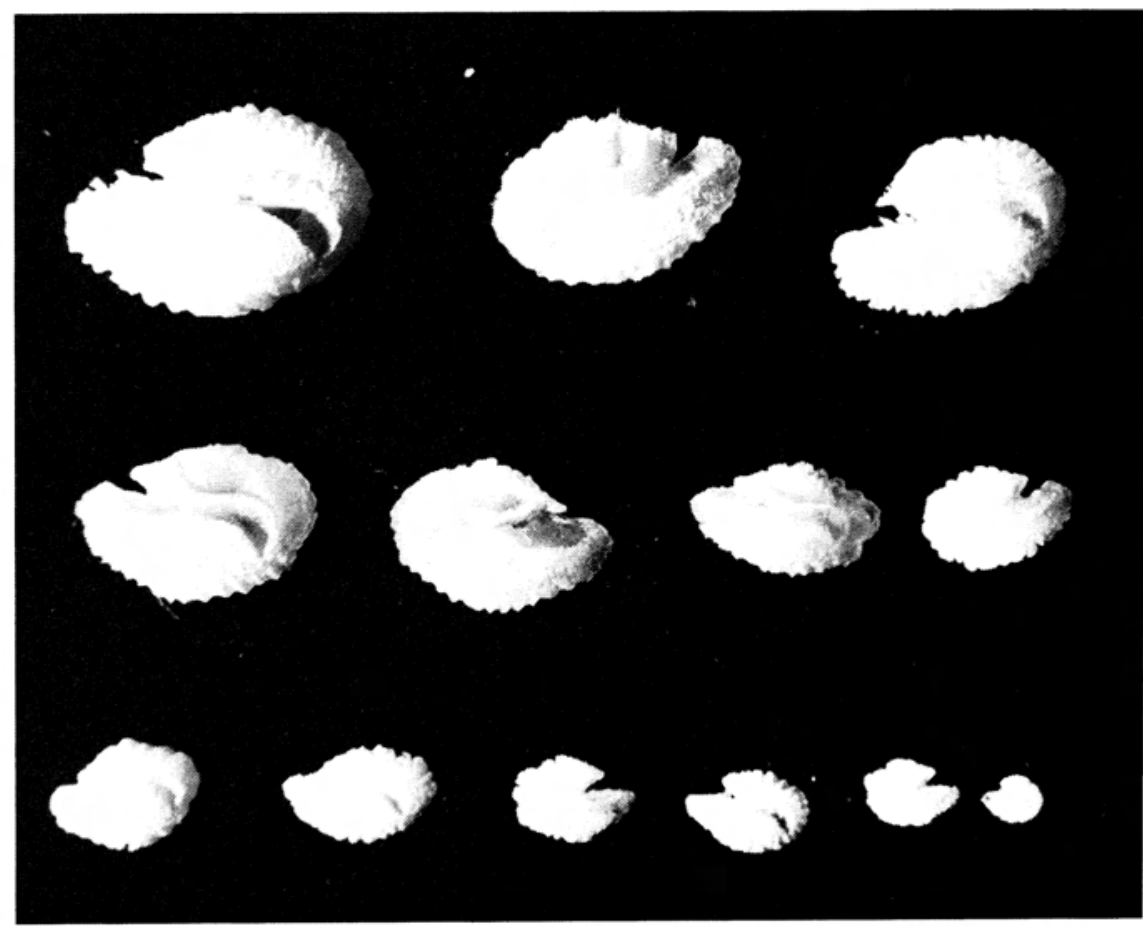

Fig. 4c. The sagittal otoliths of Oreochromis mossambicus from the Klein Tshipise Hot Spring. 


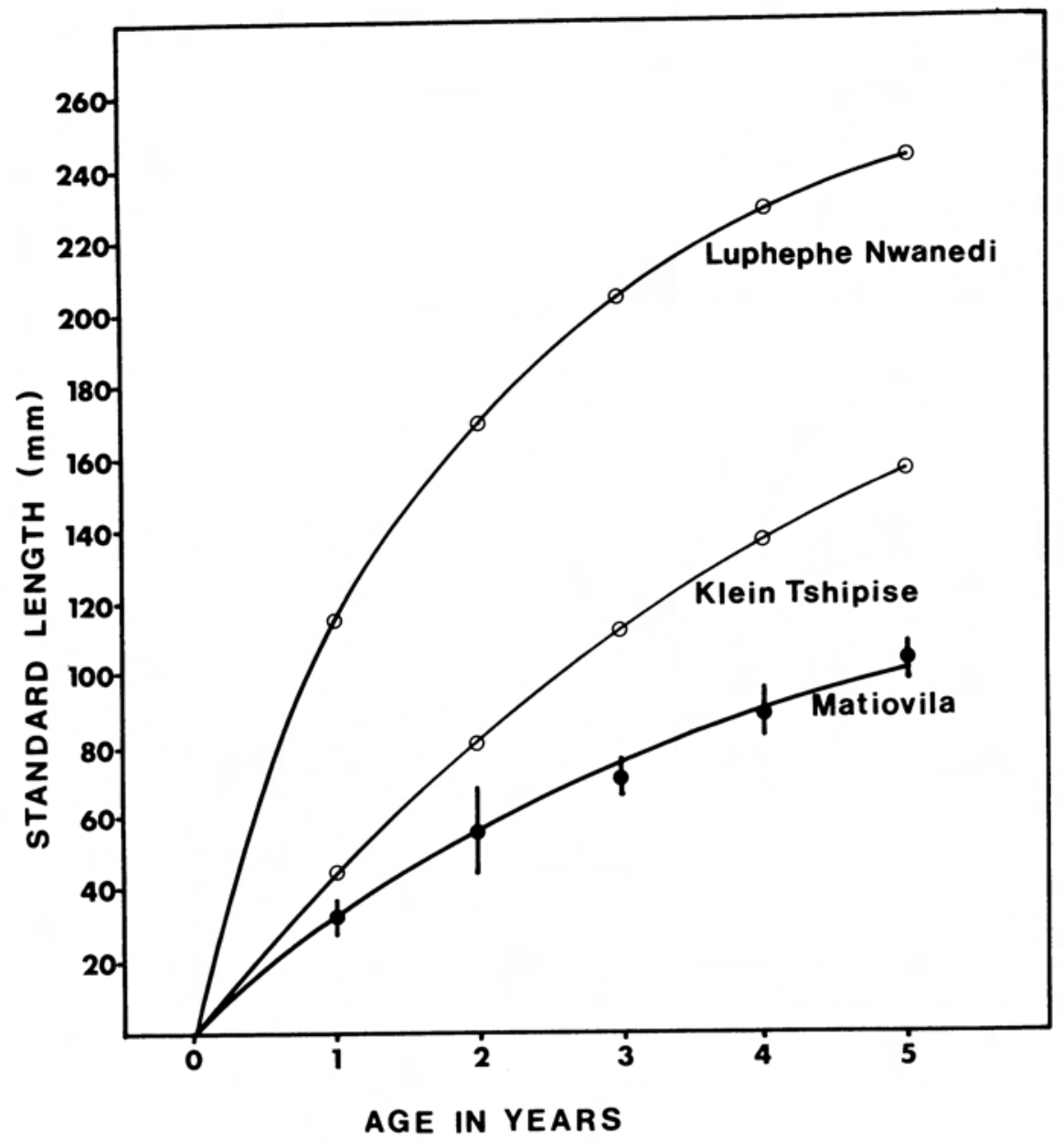

Fig. 5. Von Bertalanffy growth curves of Orevchromis mossambicus from the Luphephe/Nwanedi impoundment (Hecht 1980), from the Klein Tshipise Hot Spring (Hecht \& Jackson in prep.) and from the Matiovila Hot Spring in the Kruger National Park. The mean observed length at age \pm standard deviation is also indicated for the Matiovila fish.

Apart from the area immediately surrounding the eye of the spring, the substratum of the entire system is covered with a layer of detritus. Bowen (1979) in a detailed study on detrivory in Lake Sibaya observed that detrital matter is the most important component of the diet of this species. Similarly the bulk of the stomach contents of the Matiovila fish also consisted of detritus. 
Table 3

Benthic organisms per $225 \mathrm{~cm}^{2}$ Friedlinger Mud Grab.

(Stations are shown in Fig. 2)

\begin{tabular}{llllllll}
\hline Stations & A1 & A2 & B1 & B2 & C & D1 & D2 \\
\hline Chironomidae & - & - & 10 & 5 & 8 & 18 & 38 \\
Ephemeroptera & - & - & 1 & - & 1 & - & - \\
Odonata & - & - & - & - & 1 & - & - \\
Chaeborus & - & - & - & - & - & 1 & - \\
Coleoptera & - & - & 1 & - & - & - & - \\
\hline
\end{tabular}

\section{Discussion}

From the preceding results it can definitely be concluded that the Matiovila tilapia are severely stunted, even more so than those from Klein Tshipise. The question, however, arises as to which factor or combination of causative factors are responsible for their small size.

Iles (1973) pointed out that stunting increases the reproductive potential of a population. As a consequence breeding at frequent intervals is therefore one of the most obvious and characteristic features of stunted tilapias. Precocious breeding and stunting of tilapia in ponds has always been a major problem to the aquaculturalist (Lovshin 1982). Vaas \& Hofstede (1952) and Chen (1953) for example reported that tilapia under culture conditions in Indonesia and Taiwan can produce a brood every 20-40 days.

Bearing the above in mind, the hypothesis proposed for the Klein Tshipise fish (Hecht \& Jackson in prep.) was that as a result of the high water temperatures $\left(27^{\circ} \mathrm{C}-36,7^{\circ} \mathrm{C}\right)$ the fish were reproducing throughout the year resulting in the system becoming overcrowded. This in turn resulted in decreased food availability, in terms of both quality and quantity, which might have become a somatic growth limiting factor. In essence this hypothesis is similar to Bowen's (1979) explanation for the stunted growth of O. mossambicus in Lake Sibaya.

Considering the population in the Matiovila system this argument obviously does not hold true as food appears to be abundant and would therefore not act as a growth-limiting factor. Moreover they also have the ability to breed throughout the year.

It can therefore be argued that we should not view the small size of the fish as a direct result of some or other limiting factor, but should rather seek an explanation in terms of the fish having adapted themselves to a particular set of environmental conditions, as a result of which they are "old for their size" rather than "small for their age" (Noakes \& Balon 1982).

Iles (1973) proposed the following thesis as an explanation for stunting, that some stimulus triggered by numerous factors such as habitat size and depth, higher temperatures and physico-chemical water properties results in a new hormonal balance controlling both reproduction (increased) and growth 
(decreased). This thesis to a large extent ascribes stunting to density independent factors. However, considering the size of the Matiovila system, it is our contention that density dependent factors could play an equal, if not greater, role in determining population size, growth and individual asymptotic length.

Considering that young small tilapia have a higher temperature tolerance than older and large individuals (Welcomme 1965) and high levels of total dissolved solids increases resistance to higher temperatures (Allanson \& Noble 1964; Halsband in Macan 1961) and that higher temperatures are generally condusive to breeding in tilapiine fishes, it can possibly be assumed that the high conductivity of the Matiovila water increases their tolerance to higher temperatures, which in turn acts as one of the stimuli for all year round breeding.

Bearing the above in mind and considering that an earlier age and smaller size at first maturity will have a great effect on the rate of population increase (Emlen 1973; Southwood 1976) (cf. age and size at first maturity for Matiovila and Luphephe/Nwanedi fish), it would seem reasonable to assume that the Matiovila population should be considerably larger, i.e. up to a point when density dependent factors effectively begin to regulate population size. Yet the population has remained small and constant for several years (P. Zway, pers. obs.). It is quite possible that this is due to high levels of efficient predation by otters, herons, darters, cormorants and giant and other kingfishers, all of which have been observed at or near the system.

The above discussion therefore leads to the conclusion that the small size of the Matiovila tilapia is an adaptation to environmental conditions rather than one of stunting due to constrained somatic growth. The adaptation in this case being directed towards earlier maturation in a condusive reproductive climate, resulting in increased recruitment and a quicker generation time. In the case of the Matiovila fish, stunting may therefore be interpreted as a survival mechanism against possible high mortalities caused by predation.

Should our interpretation be correct then this theory would add extra credibility to the hypothesis that tilapiine fishes, in general, show a high degree of phenotypic and environmental plasticity.

\section{Acknowledgements}

Sincere thanks are due to the Warden of the Kruger National Park for permission to visit the Matiovila Hot Springs, to collect samples and for permission to publish the results. The Anglo American Corporation of S.A., Mobil Oil (S.A.) and the University of the North are thanked for their generous financial aid. Dr A.J. Ribbink is thanked for the valuable comments on the manuscript.

\section{REFERENCES}

ALLANSON, B.R. and R.G. NOBLE. 1964. The tolerance of Tilapia mossambica (Peters) to high temperature. Trans. Am. Fish. Soc. 93: 323-332.

BOWEN, S.H. 1979. A nutritional constraint in detritivory by fishes: the stunted population of Sarotherodon mossambicus in Lake Sibaya, South Africa. Ecol. Monogr. 49(1): 17-37. 
BRUTON, M.N. and B.R. ALLANSON. 1974. Growth of Tilapia mossambica (Peters) (Pisces: Cichlidae) in Lake Sibaya, South Africa. J. Fish. Biol. 6: 701-715.

CHEN, T.P. 1953. The culture of Tilapia in rice paddies in Taiwan. Fish. Ser. No. 2. Chinese-American Commission on Rural Reconstruction, Taipei, Taiwan: 29 pp.

COE,M.J. 1965. Tilapia grahami Boulenger - A study in environmental extremes. J. Appl. Ecol. 2: 414.

COE, M.J. 1966. The biology of Tilapia grahami Boulenger in Lake Magadi, Kenya. Acta Trop. 23: 147-177.

DU PLESSIS, S.S. 1951. Stunted fish and pygmyism. S. Afr. J. Sci. 47: 286.

EMLEN, J.M. 1973. Ecology: An evolutionary approach. New York: Addison Wesley.

GARROD, D.J. and H.Y. ELDER. 1960. The fishery on Lake Naivasha. E. Afr. freshw. fish. res. Org. Ann. Rep. 1960: 24-25.

HECHT, T. 1978. A descriptive systematic study of the otoliths of the Neopterygean marine fishes of South Africa. Part I. Introduction. Trans. roy. Soc. S. Afr. 43: 191-197.

HECHT, T. 1980. A comparison of the otolith and scale methods of ageing and the growth of Sarotherodon mossambicus (Pisces: Cichlidae) in a Venda impoundment (Southern Africa). S. Afr. J. Zool. 15: 222-228.

HICKLING, C.F. 1961. Tropical Inland Fisheries. London: Longmans.

NOAKES, D.L.G. and E.K. BALON. 1982. Life history of Tilapias: An evolutionary perspective. p 61-82. In: PULLIN R.S.U. and R.H. LOWE McCONNELL (Eds). The biology and culture of Tilapias. ICLARM Conference Proceedings 7, Manilla, Philippines.

ILES, T.D. 1973. Dwarfing or stunting in the genus Tilapia (Cichlidae), a possibly unique recruitment mechanism. Rapp. et process-verbaux des Reunions 164: 247-254.

ILES, T.D. and M.J. HOLDEN. 1969. Bi-parental brooding in Tilapia galilea (Pisces: Cichlidae). J. Zool., Lond. 158: 327-333.

JUBB, R.A. 1967. The freshwater fishes of southern Africa. Cape Town: A.A. Balkema.

LOVSHIN, L.L. 1982. Tilapia hybridization. In: PULLIN R.S.V. and R.H. LOWE McCONNELL (Eds). The biology and culture of Tilapias. ICLARM Conference Proceedings, 7. Manilla, Phillippines.

MACAN, T.T. 1961. Factors that limit the range of freshwater animals. Biol. Rev. 36: 151-198.

PALGRAVE, K.C. 1977. Trees of southern Africa. Cape Town: C.Struik.

PIENAAR, U DE V. 1978. The freshwater fishes of the Kruger National Park. National Parks Board of Trustees: Pretoria.

RICARDO, C.K. 1939. Report on the fish and fisheries of Lake Rukwa in Tanganyika Territory and the Bangweulu region in Northern Rhodesia. London: Crown Agents.

RICKER, W.E. 1975. Computation and Interpretation of Biological Statistics of Fish Populations. Bull. Fish. Res. Bd. Can. 191: 1-382.

SOULSBY, J.J. 1960. The Mweru-Wantipa fishing record. Rhod. agric. J. 57: 331-337.

SOUTHWOOD, T.R.E. 1976. Bionomic strategies and population parameters. In: MAY R.M. (Ed). Theoretical ecology: principles and applications. Oxford: Blackwell Sci. Publ. 
VAAS, K.F. and A.E. HOFSTEDE. 1952. Studies on Tilapia mossambica Peters in Indonesia. Contr. Inl. Fish. res. Stn., Bogor (Indonesia) 1: 1-88.

WELCOMME, R.L. 1965. Further observations on the biology of the introduced Tilapia species. E. Afr. freshw. fish. res. Org. Ann. Rep. 1964: 1824.

WHITEHEAD, R.L. 1962. The relationship between Tilapia nigra (Günther) and T. mossambica Peters in the eastern rivers of Kenya. Proc. zool. Soc. Lond. 138: 605-637.

WORTHINGTON, E.B. 1929. A report on the fishing survey of Lakes Albert and Kioga. London: Crown Agents. 